\title{
Organoleptic evaluation of pear varieties grown at different sites
}

\author{
Takácsné Hájos, M.1, Nyéki, J. ${ }^{2}$ \& Szabó, Z. ${ }^{2}$ \\ ${ }^{1}$ Debrecen University AGTC MÉK Institute of Horticulture \\ ${ }^{2}$ Debrecen University, AGTC KIT Institute of Research \& Development
}

\begin{abstract}
Summary: It was stated as a summary that a system of testing pear varieties on scale of 100 degrees, weighing 11 properties, gives a comprehensive information on qualities of pear varieties. The points of the form to be filled out, distinguishes the appreciation of accessory flavours and tastes from the main properties. Under the title of taste, sweet and acid taste are evaluated separately. The presently used system is a step forward as the composed characters do not influence the judgement of each other. In the representation of results, the 100 degree system was more efficacious than the usual 5-point system because there was no need of using fractions, and the graphic profile is more expressive, so the commodity is better visualised. The assembly of the jury was divided into two groups as below and above 35 year old persons. The two groups judged differently the acidity, sweetness and the thickness of the fruit peel. It was suggested that the choice of the produce should consider the differences in taste and give up the idea of being equally favourable for both groups. The samples of different growing sites revealed that the best quality is produced at Nagykanizsa, and this capacity would be able to supply the market also in the large super-markets and chain of department stores in Hungary.
\end{abstract}

Key words: pear varieties, organoleptic tests, acid and soluble solid content, flesh firmness, Stref-index

\section{Antecedent literature and introduction}

The purpose of pear storage is to help the sale, i.e. the continuous supply of the market (consumers) and the preservation of the position achieved on the market. Storing requires special conditions, one of them is the high relative humidity of the atmosphere in the store (90-95\%) first of all for the varieties with long fruit shape, e.g. Abate Fétel, Conference, Bosc.

The criterion of right maturity of winter pears is carefully determined: taste, flavour, smell, fusibility, which depend on optimal storing conditions, and it takes time to develop those properties. The recommended interval of temperature in the store is +0.5 and $-0.1^{\circ} \mathrm{C}$. Higher temperatures reduce the possible storing period substantially (Soltész, 1997).

As general truth we must accept that it is much more difficult to keep a good quality of pears than that of apples in the store. The cause of it is the higher intensity of respiration and the decomposition of cellulose substances, consequently the ripening process is much shorter. Further problems spring from its susceptibility to technological hazards and the uncertainty of finding the optimum time of harvest (Monzini \& Gorini, 1986). Following the after-ripening time, the right phase of maturity should be recognised by organoleptic testing. The parameters examined are partly judged according to the appearance (colour, size, form, surface), flavour, consistency and taste (aroma).

The interaction of those characters is, on the one hand, of physiological nature and cause the impression e.g. of flavour, on the other hand, of psychological nature. That's because the person of the judge, his/her sex and age may become decisive. The young people are more sensible in tasting, whereas the aged ones are more attentive and experienced (Molnár, 1991).

Depending on professional expertise, the uninstructed judges may express their preference but their opinion is otherwise rather unreliable. Another group of the organoleptic session may dispose of significant experiences. A third category of judges are specialists in this craft and are informed in technology of the industry and of the attitudes of the market. In organising organoleptic panels Meilgaard et al. (2000) forwarded suggestions, which are taken as standards (ISO 6564:1985; ISO 6658:1985; ISO 8587:1988).

A standardised panel needs an organisation of the members with coded marks (a number of four letters) and their data ought to be registered (name and address etc.). The expertise and the training are important preconditions of a successful panel, therefore it needs also a regular schooling (Guinart \& Petit, 1996). For that purpose, the Corvinus University Faculty of Alimentary Science started courses for educating professional judges for organoleptic panels.

The results of a panel session are influenced by the preparation of the samples. A basic condition is that the samples ought to be representative, that they ought to show a maximum of being related to a real population of commodities following all the official requirements and standards of the commercial practice.

The samples ought to be coded with random numbers of three letters in order to exclude any possible influence of names and numbers harboured in the minds. The judges are 
assigned to isolated rooms (cabinets) to exclude any troublesome moment, noise, smell or light, etc. Temperature should be $20^{\circ} \mathrm{C}$, relative humidity 50-70\% (ISO 8587: 1988).

For the mathematical processing of data obtained by the organoleptic session the profile-analysis is recommended, and the results are expressed in a profile polygon. The figure is then checked by the statistical software: ProfiSence (Kókai et al., 2002).

The purpose of our organoleptic pear panel was the examination of effects of storing practices on the quality of pear fruits originated from different growing sites and sent on the market for immediate fresh consumption. The quality parameters are transformed to numbers. The ripening and after-ripening was also examined as specific for the respective varieties.

\section{Material and method}

Measurements are performed in 2010 February 11 on the Debrecen University, Agricultural and Technical Centre. The samples are presented in Table 1.

Table 1. Code, variety of pear samples and their origin

\begin{tabular}{|c|c|c|}
\hline Code & Variety & Origin \\
\hline 435 & Packham's Triumph & Tesco \\
\hline 397 & Packham's Triumph & Csenger \\
\hline 719 & Packham's Triumph & Nagykanizsa \\
\hline 781 & Packham's Triumph & Spar \\
\hline 456 & Packham's Triumph & CBA \\
\hline 838 & Bosc kobak & Csenger \\
\hline 446 & Bosc kobak & Nagykanizsa \\
\hline 983 & Bosc kobak & Tesco \\
\hline 630 & Bosc kobak & Nagykanizsa \\
\hline 688 & Fétel apát & Nagykanizsa \\
\hline 931 & Conference &
\end{tabular}

Instrumental tests are made in the Laboratory: soluble solid content (Brix \%), acids (\%) and flesh firmness $\left(\mathrm{N} / \mathrm{cm}^{2}\right)$. Fruit size was expressed as a mean mass ( $\mathrm{g}$ ) of 10 pears, width and height $(\mathrm{mm})$ and their relation as the form index.

The fertilisation was estimated from the number and ratio of normal and empty seeds, as a parameter of fertility (Nyéki et al., 1998).

The state of maturity was measured by the starch test according to the method developed on the Fruit Growing Department of the Corvinus University. Those data, soluble solids and flesh firmness together give the Streif-index according to the formula:

\section{Streif-index: $T / S T x S$}

Where T: flesh firmness, $\mathrm{N} / \mathrm{cm}^{2}$

ST: soluble solids (Brix\%)

$\mathrm{S}$ : the scale of starch content.

Our experiences prove that the Streif-index is successfully used not only for apples but also to pears
(Göndör, 2000). The value is indicating the optimal state of consumer's quality.

In the organoleptic sessions we applied the points presented in Table 2 .

Table 2. Viewpoints of the organoleptic panel for the jury

\begin{tabular}{|c|c|c|}
\hline appearance & faulty ........................................faultless & $1 \ldots . .100$ points \\
\hline skin colour & too pale or dark.....typical for the pear & $1 \ldots . .100$ points \\
\hline thickness of the peel & too thick ..................................... thin & $1 \ldots . .100$ points \\
\hline chewing consistency & hard, dry..... & $1 \ldots . .100$ points \\
\hline $\begin{array}{l}\text { flavour } \\
\text { (while chewing) }\end{array}$ & undistinctive. & $1 \ldots . .100$ points \\
\hline accessory smell & strong ............................non existing & $1 \ldots \ldots 100$ points \\
\hline taste, aroma (pear) & ......intense & $1 \ldots . .100$ points \\
\hline accessory taste & .......................absent & $1 \ldots . .100$ points \\
\hline taste sweetness & ......optimal & $1 \ldots . .100$ points \\
\hline taste sourness & feeble or exaggerated..............optimal & $1 \ldots . .100$ points \\
\hline sympathy & antipathetic ..............very sympathetic & $1 \ldots . .100$ points \\
\hline
\end{tabular}

Every item was placed on two dishes. On one dish the whole fruits are put, on the other, the sliced fruit was also presented. That way, opinions could be formed related to the peel and flesh, smell and taste, the presence and absence of flavour and taste, etc. The number of points to be given was uniformly 1 to 100 , instead of the former applied 1 to 5 scale. Thus the scale could be extended and made more spectacular. For negative impressions, there was a row left for describing suggestions.

For evaluating the varieties, means and variances are applied. For the expression of the properties together, profile polygons are drawn. The comparison of samples originating from different growing sites was possible for two leading varieties: Packham's Triumph and Bosc.

The board of the jury comprised 22 persons, 10 of them were older than 35 years, and 12 were younger, so the evaluation could be divided according to the two categories.

\section{Results and discussion}

The main decisive properties of the winter pear mature for fresh consumption are its acidity, soluble solids content and its firmness. The data of four varieties examined show the most differences in the firmness of the flesh (Figure 1). Among the two leading varieties (Packham's Triumph and Bosc) the latter produced higher values. Subsequently, Abate Fétel was also characterised by more consistent (firm) flesh. In acid and soluble solids content, no statistically proved differences could be found. The ratio of entire and empty seeds signalised the conditions of fertilisation. In Figure 2, it is evident that the two leading varieties and the Conference showed higher ratio volt empty seeds, whereas the French variety Abbé Fétel had the lowest parameters (of entire seeds), which is allegedly an insufficiency of the variety.

For the expression of maturity, the Streif-index is used also for pear not only for apple. Figure 3 shows that the data 
of Packham's triumph samples varied widely, whereas the Bosc and Abbé Fétel samples were more ripe suitable for organoleptic tests.

Figure 4 presents the Streif-index data of the samples of Packham's Triumph. As visible, the samples of code numbers 435 and 456 seem to be unripe producing low values of the Streif-index. This is supported by the flesh firmness data of Figure 5, wehereas the samples of Bosc were more uniform.

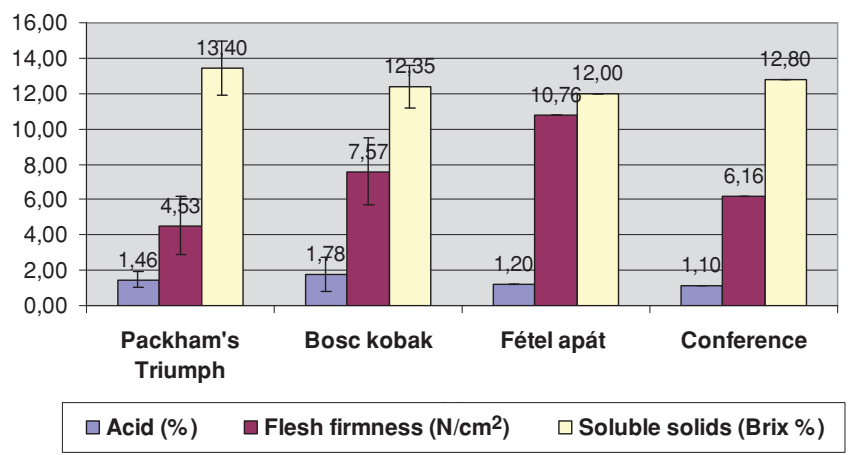

Figure 1. Data of inner quality in pear fruits grown at different sites

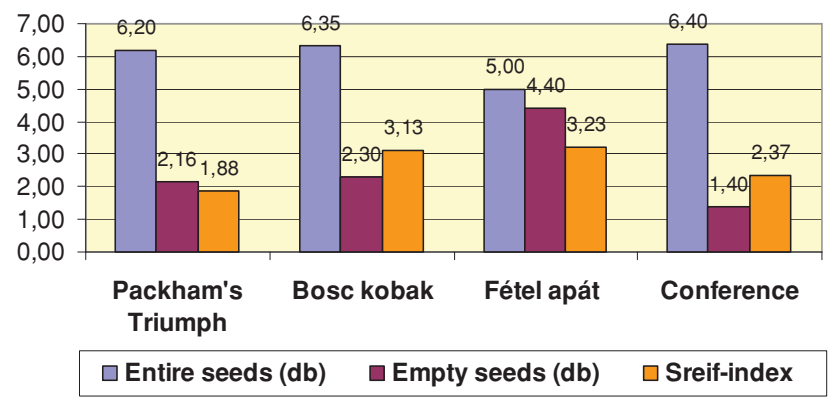

Figure 2. The ratio of entire and empty seeds in pear fruits grown at different sites

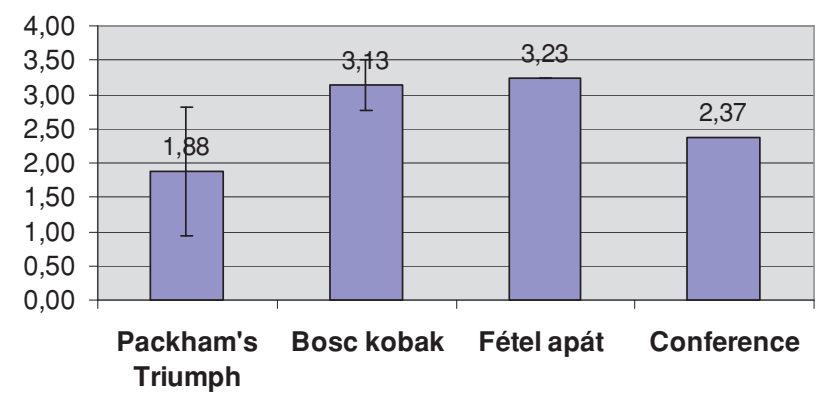

$\square$ Sreif-index T/ST*S

Figure 3. The Streif-index values as means of the samples

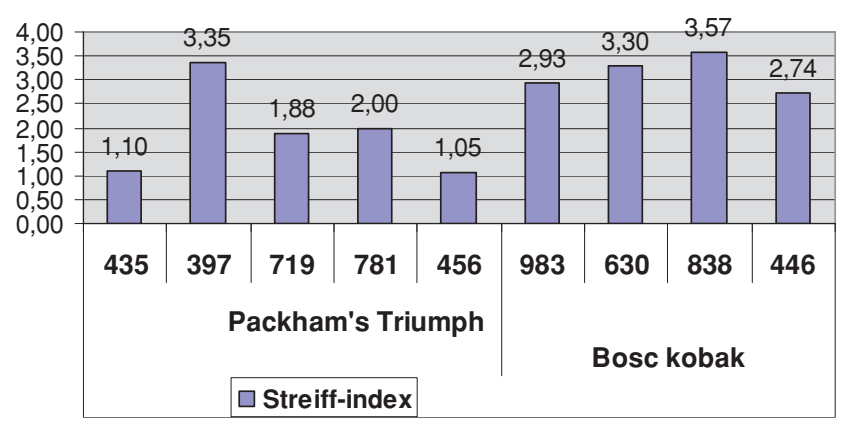

Figure 4. Streif-index values of Packham's Triumph and Bosc samples

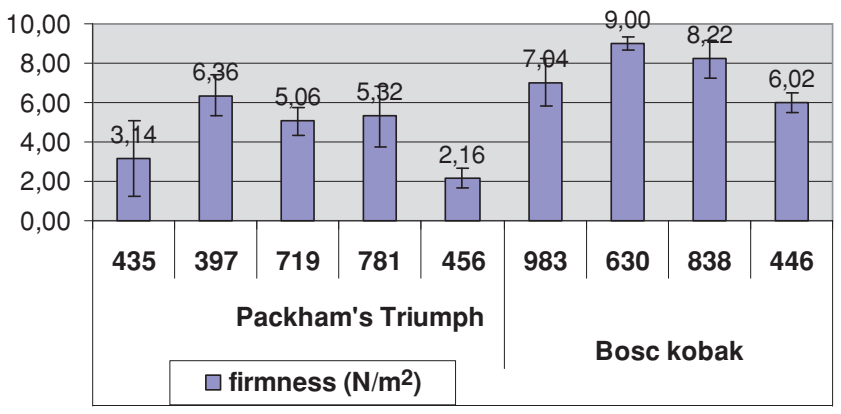

Figure 5. Flesh firmness data in Packham's Triumph and Bosc pear samples

The shape index shows the typical forms of the pear varieties, but it varied also at the growing sites (Figure 6). Fruits of Packham's Triuph showed lower, Bosc higher ones corresponding to the form of the variety.

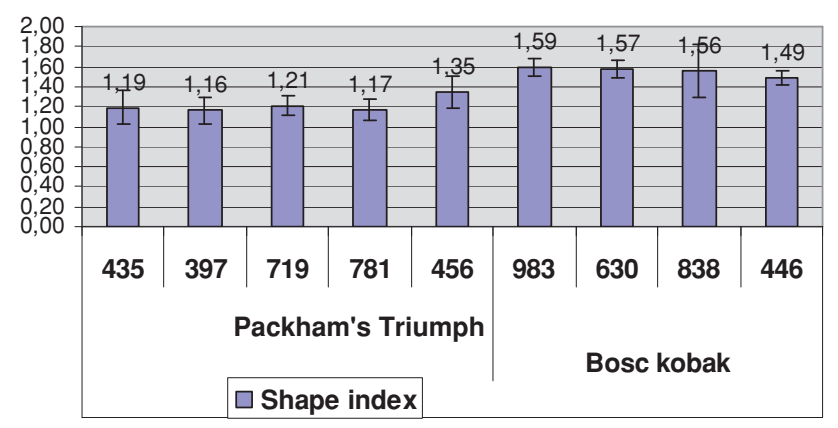

Figure 6. The shape index of Packham's Triumph and Bosc fruit samples

The distribution of mass (weight) of fruits is shown in Figure 7. The sample number 456 was markedly small but the results of the organoleptic panel are also included (Figures 8 and 9), which had relatively low values. The best values of Packham's Triumph are found in sample number 719 given by both age group of the jury, and this sample was grown at Nagykanizsa. This outstanding growing site and technology excelled. The data of the figures prove that the persons elder than 35 years judged the acidity of samples negatively, which should mean that the samples were less sour than desired (Figure 10).

The properties of the Bosc samples seem to be more balanced (Figures 11 and 12) according to the age group above 35 years, at the same time, the age group below 35 years gave lower grades to the sample number 446 (Figure 10). It is clearly recognised that the judgement differed in the two age groups of the jury related to thickness of the skin and

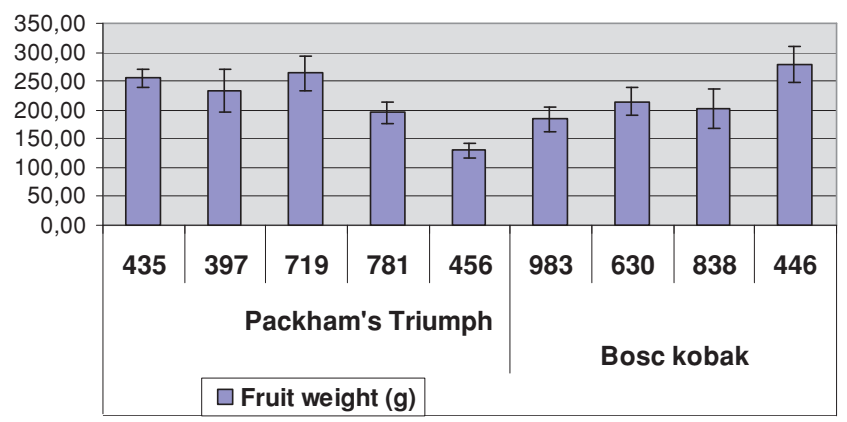

Figure 7. Fruit weight (g) in samples of Packham's Triumph and Bosc kobak varieties 
they missed the components of the pear taste. Regarding the judgements of both age groups over the assembly of samples (Figure 13 and 14), the younger jury was more susceptible in distinguishing between acidity and sweetness, and sweetness was decisive in rising sympathy for the respective sample.

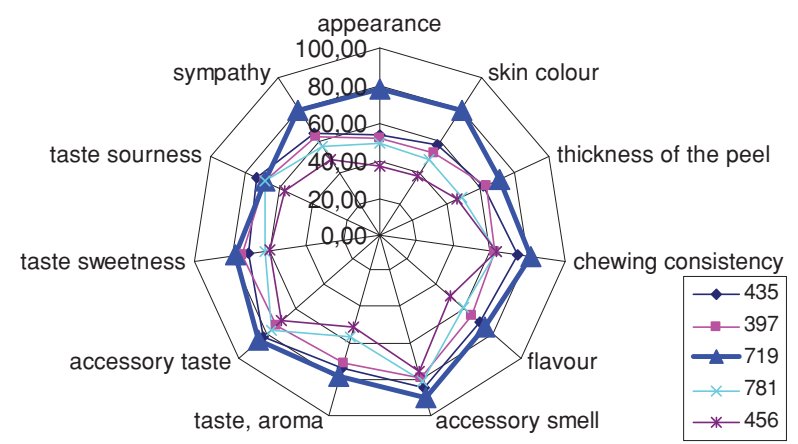

Figure 8. Organoleptic test of Packham's Triumph samples by judges beyond 35 year old

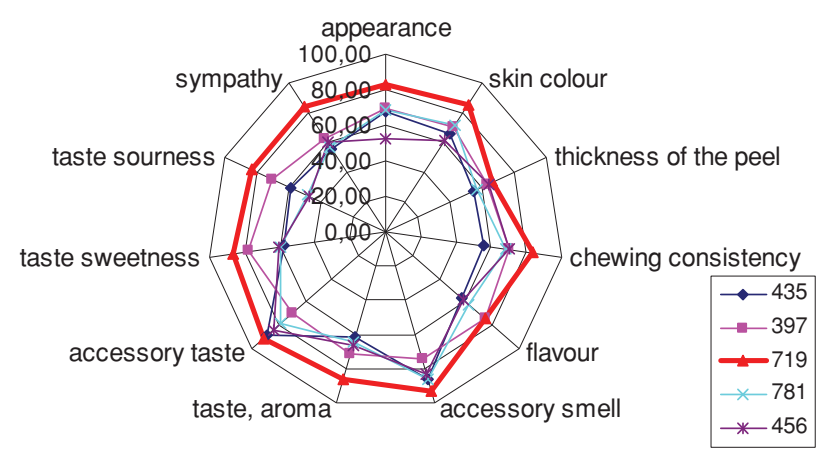

Figure 9. Organoleptic test of Packham's Triumph samples by judges younger than 35 year

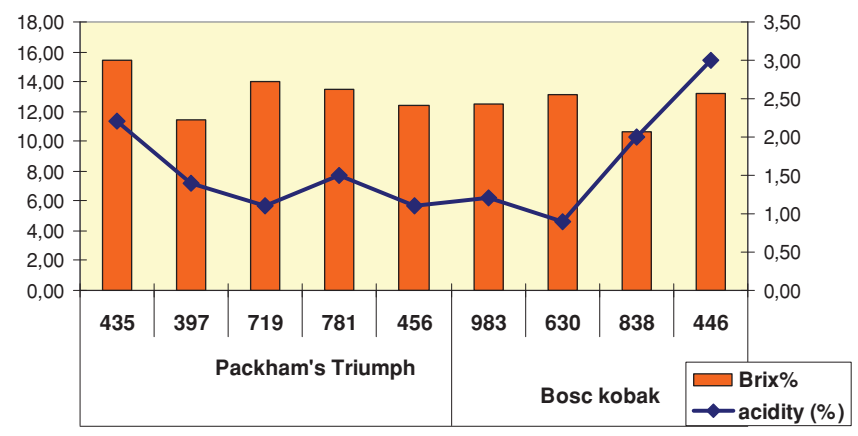

Figure 10. Acidity and soluble solids content of pear samples

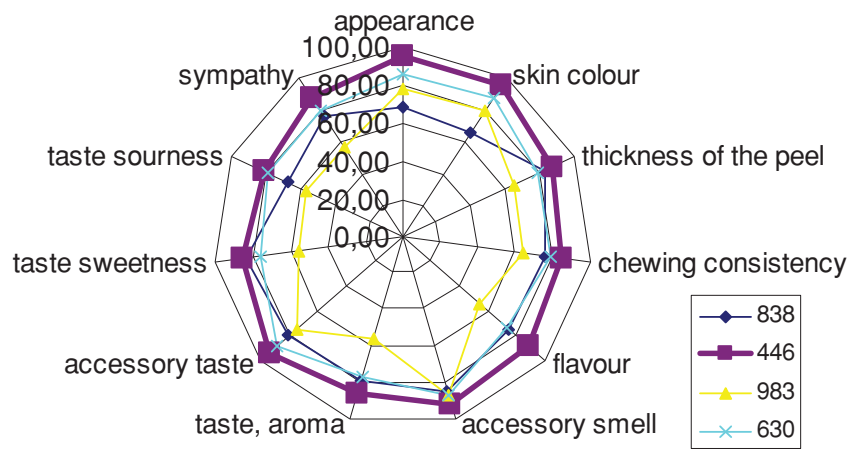

Figure 11. Organoleptic tests of Bosc samples judged by the age group older than 35 years

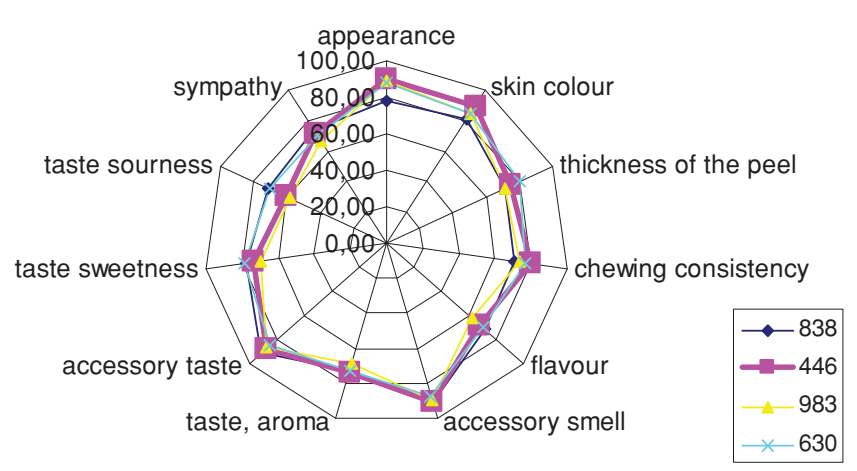

Figure 12. Organoleptic tests of Bosc samples judged by the age group below 35 years

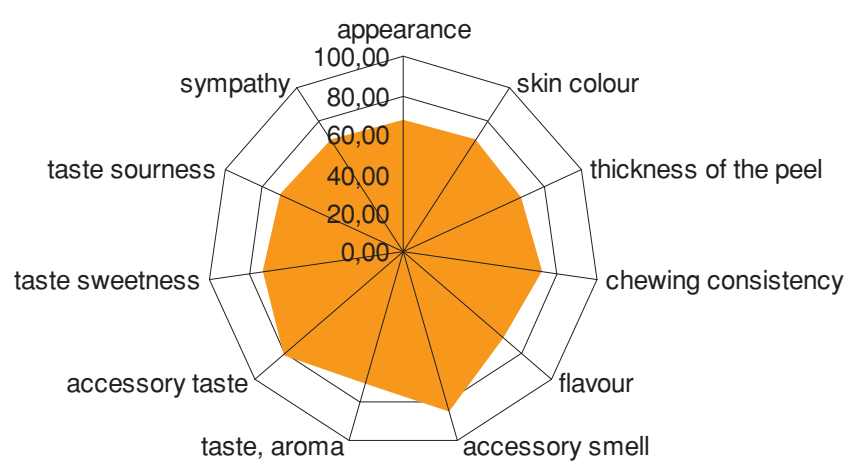

Figure 13. Organoleptic judgement of the mean of pear samples by the age group above 35 years

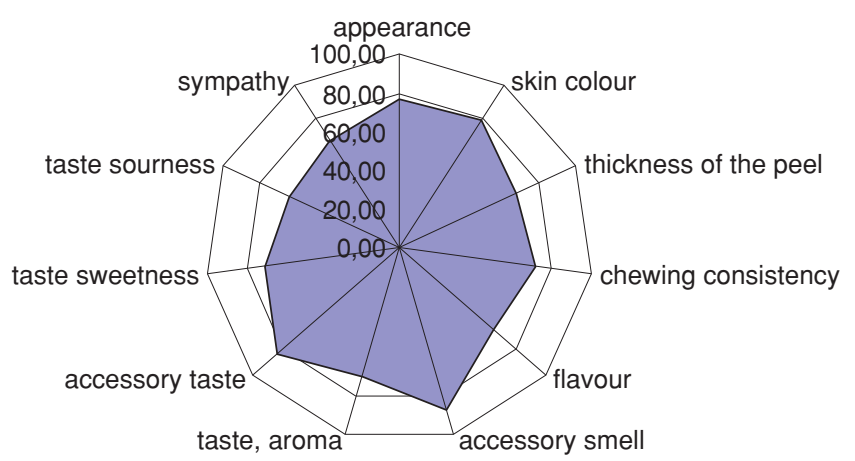

Figure 14. Organoleptic judgement of the mean of pear samples by the jury of age group below 35 years

\section{Acknowledgements:}

The research was supported by the project OM00042/2008.

\section{References}

Guinart, J.X. \& Petit, V. (1996): Assessment of sensory quality, and relation with descriptive analysis ratings: a case study with beer. IFT annual meeting: book of abstracts, p. 147

Göndör J-né (2000): Körte. Mezőgazda Kiadó. p. 345.

ISO 6564:1985-Sensory Analysis-Methodology-Flavour profile methods

ISO 6658: 1985-Sensory Analysis-Methodology-General guidance ISO 8587:1988-Sensory Analysis-Methodology-Ranking 
Kókai Z., Heszberger J., Kollár-Hunek K. \& Kollár G. (2002): A new VBA software as a tool of food sensory tests. Hungarian Journal of Industrial Chemistry, 30: 235-239.

Meilgaard, M., Civille, G.V. \& Carr, B.T. (2000): Sensory evaluation techniques, CRC Press, Inc., 2000.

Molnár, P. (szerk.) (1991): Élelmiszerek érzékszervi vizsgálata, Akadémiai Kiadó, 178 p.
Monzini, A. \& Gorini, F. (1986): Interventi postrac-colta a valotizzazione industrielle della pera. Rivista di Frutticultura, Bologna. 3-4 (8): 20-30.

Nyéki J. \& Soltész, M. (1998): The variation of seed content of fruits in pear varieties also as function of different conditions of fertilization, as open pollination, natural autogamy and allogamy. Acta Horticulturae. 475: 237-250.

Soltész M. (1997): Integrált gyümölcstermesztés. Mezőgazda Kiadó. p. 842. 